\title{
Sintesis Membran Elektrolit Padat Berbahan Dasar Kitosan
}

\section{Synthesis of Chitosan-Based Solid Electrolyte Membrane}

\author{
Diana Eka Pratiwi ${ }^{1 *}$ \\ 1) Program Studi Kimia, Universitas Negeri Makassar

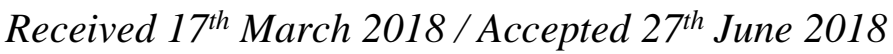

\begin{abstract}
ABSTRAK
Kemajuan pesat teknologi menyebabkan peningkatan kebutuhan baterai, salah satunya baterai ion litium. Baterai litium memiliki cairan elektrolit yang mudah terbakar bila mengalami kebocoran elektrolit dan logam lithium dalam baterai akan bereaksi dengan air, sehingga memproduksi gas hidrogen yang eksplosif. Saat ini elektrolit bermatriks padatan sebagai elektrolit baterai telah banyak dikembangkan. Kitosan merupakan salah satu jenis polimer alam yang berpotensi sebagai bahan elektrolit padat. Penambahan kation dengan massa atom rendah seperti ion litium (Li+) di dalam membran polimer memungkinkan suatu proses transfer muatan yang efisien.. Penelitian ini merupakan penelitian eksperimen yang bertujuan untuk mensintesis membran elektrolit padat berbahan dasar kitosan. Sampel kitosan yang digunakan merupakan kitosan yang memiliki derajat deasetilasi sebesar $98 \%$. Membran elektrolit kitosan$\mathrm{LiOH}$ disintesis menggunakan metode blending dengan perbandingan konsentrasi kitosan-LiOH sebesar (100:0), (95;5), (90:10), (85:15), dan (84:16)\% b/b. Membran yang diperoleh dikarakterisasi warna dan ketebalannya, diukur konduktivitasnya menggunakan alat LCR meter, dan dianalisis derajat kristalinitasnya dengan alat X-Ray Diffraction (XRD). Dari hasil penelitian diperoleh membran kitosan-LiOH berwarna kuning jernih dengan ketebalan rata-rata sebesar 0,1 mm, dengan konduktivitas tertinggi diperoleh pada perbandingan konsentrasi kitosan-LiOH sebesar (85:15) \% b/b.
\end{abstract}

Kata kunci: membran elektrolit, kitosan, LiOH, konduktivitas.

\begin{abstract}
The rapid advancement of technology leads to an increase in battery demand, one of which is lithium ion batteries. Lithium batteries have flammable liquid electrolytes when electrolyte leaks, and lithium metals in the battery will react with water, producing explosive hydrogen gas. Currently electrolytic solids as battery electrolytes have been widely developed. Chitosan is one type of natural polymer that has the potential as a solid electrolyte material. The addition of a cation with a low atomic mass such as lithium ions $(\mathrm{Li+})$ inside the polymer membrane enables an efficient charge transfer process. This study is an experimental study aimed at synthesizing a chitosan-based solid electrolyte membrane. The chitosan sample used is chitosan which has deacetylation degree of $98 \%$.
\end{abstract}

*Korespondensi:

email: diana.eka.pratiwi@unm.ac.id 
The chitosan-LiOH electrolyte membrane was synthesized using blending method with the ratio of chitosan-LiOH concentration of (100: 0), (95: 5), (90:10), (85:15), and (84:16) \% $w / w$. The membrane obtained was characterized by color and thickness, determination of conductivity using LCR meter, and degree of crystallinity analysis with $X$-Ray Diffraction (XRD) tool. From the result of the research, clear yellow chitosan$\mathrm{LiOH}$ membrane was obtained with an average thickness of $0.1 \mathrm{~mm}$, with the highest conductivity obtained with the ratio of chitosan-LiOH concentration of (85:15) \% w/ $w$.

Keywords: electrolyte membrane, chitosan, LiOH, conductivity

\section{PENDAHULUAN}

Kemajuan pesat teknologi menyebabkan peningkatan kebutuhan baterai, salah satunya baterai ion litium. Baterai litium memiliki cairan elektrolit yang mudah terbakar bila mengalami kebocoran elektrolit dan logam lithium dalam baterai akan bereaksi dengan air, sehingga memproduksi gas hidrogen yang eksplosif. Masalah lain yang dapat ditimbulkan adalah semakin meningkatnya material beracun dan berbahaya di lingkungan akibat pembuangan limbah baterai tersebut. Oleh karena itu orang beralih kepada elektrolit bermatriks padatan sebagai elektrolit baterai. Membran elektrolit padat yang ideal harus memiliki stabilitas kimia, stabilitas termal konduktivitas proton yang tinggi, fleksibilitas tinggi, biaya yang rendah dan ketersediaan bahannya yang melimpah di alam (Yuan, et al. 2009 ; Fonseca, and Neves 2006 dalam Yulianti dkk, 2013).

Berbagai jenis material terus dikembangkan dalam pembuatan elektrolit padat baterai. Penggunaan polimer sintetis sebagai bahan elektrolit padat ternyata masih memiliki beberapa kekurangan. Selain harganya yang mahal, dampak lingkungan akibat menumpuknya sampah kimia juga menjadi salah satu permasalahan yang sering muncul. Kembali ke alam merupakan solusi yang paling di rekomendasikan untuk mengatasi masalah tersebut. Kitosan merupakan salah satu jenis polimer alam yang berpotensi sebagai bahan elektrolit padat. Kitosan adalah biopolimer karbohidrat alam yang diturunkan dari proses deasetilasi kitin. Kitin sendiri merupakan senyawa biopolimer kedua yang paling banyak ditemukan dialam setelah selulosa (Rinaudo , 2006 dalam Yulianti dkk, 2013). Membran kitosan dibuat dengan metode inversi fasa menggunakan bahan baku yang berasal dari cangkang hewan crustaceae, terutama udang melalui serangkaian proses, diantaranya depigmentasi, deproteinasi, demineralisasi, dan deasetilasi. Oleh karena sifat kristalin kitosan, bagian kristalin pada kitosan akan menghalangi masuknya molekul air ke dalam membran kitosan sehingga menghambat transpor ion hidroksida di dalam membran yang didukung dengan adanya gugus polar dan non polar yang dikandungnya. Dengan demikian kitosan dapat digunakan sebagai pengental, pengikat, penstabil, pembentuk tekstur, dan pembentuk gel. Bila kitosan dilarutkan di dalam asam, maka kitosan akan menjadi polimer kationik dengan struktur linear sehingga dapat digunakan dalam proses flokulasi dan pembentukan film. Kitosan dapat dijadikan konduktor proton, jika kitosan dilarutkan dalam asam asetat dan dicetak dalam bentuk lembaran. Ion $\mathrm{H}+$ dan $\mathrm{CH} 3 \mathrm{COO}$ - tersebar di dalam pelarut kitosan dan dapat dimobilisasi di bawah medan listrik. Jika ion $\mathrm{H}+$ lebih banyak yang bergerak di 
dalam film maka akan menjadi konduktor proton. Membran kitosan dibuat dengan metode inversi fasa menggunakan bahan baku yang berasal dari cangkang hewan crustaceae, terutama udang melalui serangkaian proses, diantaranya depigmentasi, deproteinasi, demineralisasi, dan deasetilasi.

Menurut Rahmawati dan Siang (2013) membran elektrolit polimer kitosan dengan penambahan LiClO4 memiliki nilai konduktivitas 8.96 x 10-6 S/cm. Kation dengan massa atom rendah seperti ion litium $(\mathrm{Li}+)$ di dalam membran polimer memungkinkan suatu proses transfer muatan yang efisien. Ion dengan massa atom rendah seperti ion litium ( $\mathrm{Li}+)$ menjadi pilihan sebagai sumber muatan dalam membran elektrolit polimer karena berat atomnya kecil sekitar 6,94 g/mol, sehingga lebih mudah (ringan) untuk mobilitas dalam membran elektrolit polimer (Efhana dan Mochamad, 2014). Litium $(\mathrm{Li}+)$ dalam bentuk senyawa Litium Hidroksida $(\mathrm{LiOH})$ termasuk basa kuat dan memiliki derajat ionisasi 1 atau mengalami ionisasi sempurna (Poppy, dkk; 2007). Derajat ionisasi yang tinggi menjadi dasar digunakannya sebagai sumber elektrolit.

Penelitian ini bertujuan untuk mensintesis membran elektrolit padat berbahan dasar kitosan dengan penambahan larutan $\mathrm{LiOH}$ sebagai sumber muatan agar dihasilkan membran elektrolit polimer dengan konduktivitas yang cukup tinggi.

\section{METODE}

Alat. Alat-alat yang digunakan pada penelitian ini di antaranya alat-alat gelas yang umum digunakan, LCR meter, alat difraksi sinar-X (XRD), neraca, hot stirrer, magnetic stirrer, neraca analitik, spatula, dan cetakan flexyglass.

Bahan. Bahan yang digunakan dalam penelitian ini adalah kitosan, larutan $\mathrm{CH} 3 \mathrm{COO}$ $2 \%$, padatan $\mathrm{LiOH}$, larutan $\mathrm{HCl} 0,1 \mathrm{~N}$, aluminium foil, dan akuades.

Pembuatan larutan elektrolit polimer kitosan: LiOH. Larutan elektrolit polimer dibuat dengan metode blending dengan cara melarutkan kitosan dan $\mathrm{LiOH}$ dalam $\mathrm{CH} 3 \mathrm{COOH} 2 \%$ pada berbagai perbandingan komposisi ( $95: 5,90: 10,85: 15$ ) kemudian dilakukan pengadukan dengan menggunakan perangkat hot-strirrer untuk mendapatkan larutan polimer yang homogen. Larutan homogen kemudian dimasukkan ke dalam cetakan flexyglass kemudian di keringkan pada suhu kamar hingga kering dan terbentuk membran.

Karakterisasi membran elektrolit polimer kitosan: LiOH. Membran elektrolit polimer kitosan : LiOH yang terbentuk dikarakterisasi warna dan ketebalannya, selanjutnya masing-masing diuji nilai konduktivitasnya dengan LCR meter, membran elektrolit polimer dengan nilai konduktivitas tertinggi kemudian dianalisis dengan XRD.

\section{HASIL DAN PEMBAHASAN}

Pembuatan membran elektrolit polimer Kitosan: LiOH. Kitosan yang digunakan adalah kitosan yang lolos ayakan 30 Mesh dengan tujuan untuk memperluas permukaan 
sehingga memudahkan kelarutannya pada asam asetat $2 \%$. Kitosan yang dilarutkan dalam asam asetat akan mengalami protonasi pada gugus aminanya menjadi -NH3+.

Karakterisasi membran elektrolit polimer kitosan: LiOH. Membran elektrolit polimer yang telah kering berwarna bening kekuningan dengan ketebalan rata-rata 0,10 $\mathrm{mm}$. Semakin tipis membran maka semakin baik pergerakan elektron di dalam membran elektrolit polimer. Menurut Zulfikar, dkk (2009) semakin meningkat ketebalan membran maka semakin menurun konduktivitasnya karena morfologi membran menjadi lebih padat.

Tabel 1. Ketebalan membran elektrolit polimer kitosan : LiOH

\begin{tabular}{cccc}
\hline No & $\begin{array}{c}\text { Kitosan } \\
(\boldsymbol{\%} \mathbf{b} / \mathbf{b})\end{array}$ & $\begin{array}{c}\text { LiOH } \\
(\boldsymbol{\%} \mathbf{b} / \mathbf{b})\end{array}$ & $\begin{array}{c}\text { Ketebalan } \\
(\mathbf{m m})\end{array}$ \\
\hline 1 & 100 & 0 & 0.1 \\
2 & 95 & 5 & 0.1 \\
3 & 90 & 10 & 0.1 \\
4 & 85 & 15 & 0.1 \\
5 & 84 & 16 & 0.1 \\
\hline
\end{tabular}

Masing- masing membran elektrolit polimer kemudian diukur konduktivitasnya dengan alat LCR meter, diperoleh nilai tahanan (R) yang kemudian dapat dikonversi menjadi konduktivitas.

Kebalikan dari resistivitas disebut konduktivitas $\sigma$. Adapun nilai konduktivitas suatu material bergantung dari sifat material tersebut. Konduktivitas listrik adalah kemampuan suatu bahan untuk menghantarkan arus listrik. Persamaan (1) merupakan rumus konduktivitas listrik:

$\sigma=\frac{L}{R A}$

Tabel 2. Konduktivitas membran elektrolit polimer kitosan: $\mathrm{LiOH}$

\begin{tabular}{ccccc}
\hline No & $\begin{array}{c}\text { Kitosan } \\
(\boldsymbol{\%} \mathbf{b} / \mathbf{b})\end{array}$ & $\begin{array}{c}\text { LiOH } \\
(\boldsymbol{\%} \mathbf{b} / \mathbf{b})\end{array}$ & $\begin{array}{c}\text { Resistensi } \\
(\boldsymbol{\Omega})\end{array}$ & $\begin{array}{c}\text { Konduktivitas } \\
(\mathbf{S} / \mathbf{c m})\end{array}$ \\
\hline 1 & 100 & 0 & 418.0 & 0.0241 \\
2 & 95 & 5 & 803.0 & 0.0124 \\
3 & 90 & 10 & 491.0 & 0.0251 \\
4 & 85 & 15 & 57.5 & 0.1301 \\
5 & 84 & 16 & 227.5 & 0.0440 \\
\hline
\end{tabular}

Tabel 2 menunjukkan bahwa konduktivitas tertinggi dimiliki oleh membran dengan perbandingan kitosan : $\mathrm{LiOH}(85: 15) \% \mathrm{~b} / \mathrm{b}$. Terjadi peningkatan konduktivitas pada penambahan $\mathrm{LiOH} 10 \%$ dan $15 \%$, peningkatan konduktivitas ini diduga dari makin tingginya jumlah ion dan mobilitas dari ion-ion yang ada (Riyanto, 2011). Pada penambahan $\mathrm{LiOH} 16 \%$ terjadi penurunan konduktivitas hal ini diduga karena terjadi 
kepadatan ion yang mengakibatkan terjadinya interaksi antar ion sehingga mobilitas ion dalam membran berkurang. Menurut Majid dan Arof (2005) dalam Riyanto (2011) jumlah ion yang terlalu tinggi dapat menyebabkan mobilitas ion menjadi semakin menurun, karena terjadi kepadatan ion. Jarak antara ion-ion suatu polimer tidak boleh terlalu dekat, karena dapat terjadi penggabungan ion dan membentuk pasangan ion netral yang tidak memberikan kontribusi terhadap konduktivitas.

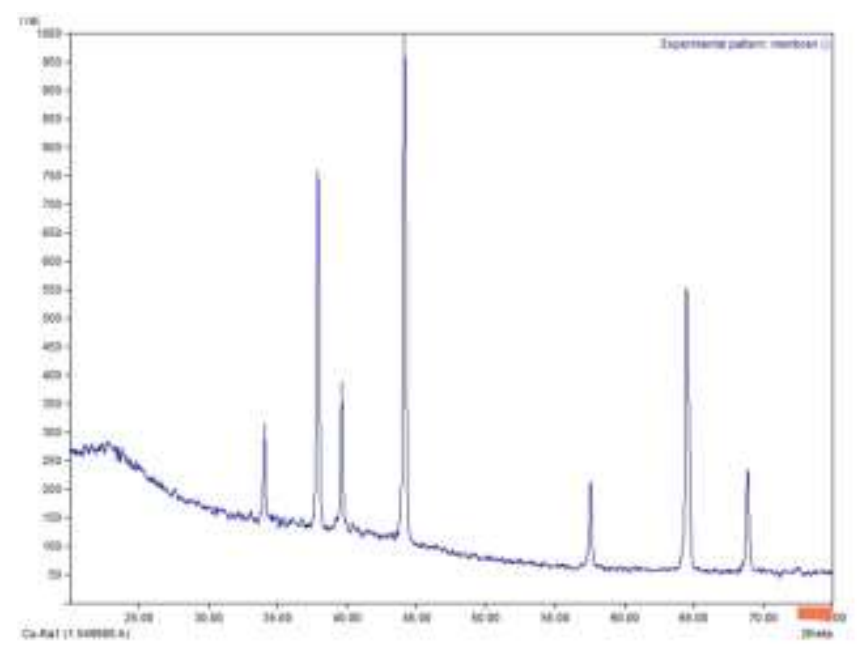

Gambar 1. Difraktogram XRD membran kitosan

Gambar 1 menunjukkan difraktogram XRD membran kitosan sebelum penambahan LiOH. Dari difraktogram terlihat bahwa kitosan berfasa amorf, sesuai dengan Sugita, dkk (2009) yang menyatakan bahwa kitosan adalah padatan amorf yang berwarna putih kekuningan.

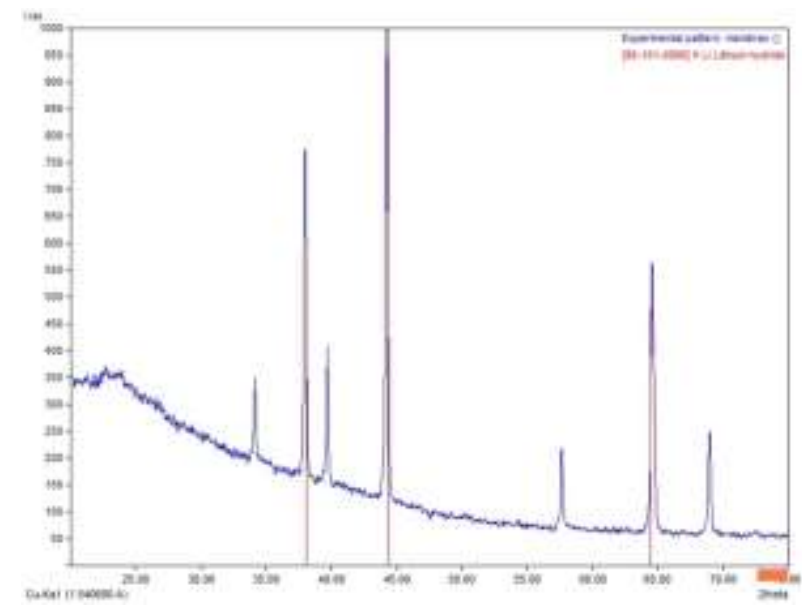

Gambar 6. Difraktogram XRD membran kitosan : LiOH (85: 15) \% b/b

Gambar 2 menunjukkan difraktogram XRD membran kitosan: LiOH dengan konduktivitas tertinggi. Dari difraktogram terlihat bahwa terjadi pergeseran intensitas menjadi lebih tinggi yang berarti fasa sedikit bergeser menjadi fasa kristal, hal ini disebabkan karena ion-ion $\mathrm{Li}+$ mengisi rongga - rongga pada membran kitosan dan menyebabkan konduktivitas meningkat. 


\section{KESIMPULAN}

Berdasarkan hasil penelitian yang diperoleh dapat disimpulkan bahwa membran elektrolit polimer dapat dibuat dari kitosan dengan sumber elektrolit larutan litium hidroksida $(\mathrm{LiOH})$ dengan perbandingan kitosan : LiOH sebesar $85: 15(\% \mathrm{~b} / \mathrm{b})$ dan menghasilkan konduktifitas sebesar 0,1301 S/cm dengan ketebalan membran 0,10 mm.

\section{DAFTAR PUSTAKA}

Efhana D.P, dan Mochamad Z. 2014. Pengaruh Variasi Waktu Penambahan Proses Kalsinasi Terhadap Prekursor Bahan Katoda Lithium Ferrophospate (LFP). Jurnal Sains Dan Seni Pomits. 3(2).

Poppy K, Setiasih S, Sidharta A. 2007. Larutan Asam, Basa, Dan Garam. Bandung: Departemen Pendidikan Nasional.

Rahmawati, dan Siang T.G. 2013. Sintesis Membran Elektrolit Untuk Aplikasi Baterai Ion Litium. Prosiding Seminar Nasional Sains Dan Matematika II Jurusan Pendidikan MIPA FKIP UNTAD ISBN 978-602-8824-49-1.

Riyanto B, Akhiruddin M, Ratna S.D. 2011. Baterai Cerdas Dari Elektrolit Polimer Kitosan-Pva Dengan Penambahan Amonium Nitrat. Jurnal Pengolahan Hasil Perikanan Indonesia. XIV(2).

Sugita P, Tuti W, Ahmad S, Dwi W. 2009. Kitosan Sumber Biomaterial Masa Depan. Bandung: Kampus IPB Taman Kencana Bandung.

Yulianti E, Rosiana D.S, Sudaryanto, H. Jodi, R. Salam. 2013. Pembuatan Bahan Polimer Elektrolit Padat Berbasis Nanokomposit Kitosan Montmorillonite untuk Aplikasi Baterai. Jurnal Kimia Kemasan. Vol.35 No.2. Oktober 2013: 77-83.

Zulfikar M.A, D. Wahyuningrum, N. Tanyela Berghuis. 2009. Pengaruh Konsentrasi Kitosan terhadap Sifat Membran Komposit Kitosan-Silika untuk Sel Bahan Bakar. Prosiding Seminar Kimia Bersama UKM-ITB VIII, Bandung, 9-11 Jun 2009. 